\section{Ketamine sedation during the treatment of retinopathy of prematurity}

throughout the UK with units using general anaesthesia, sedation combined with topical anaesthesia, and a variety of other methods.

Neonatal physiology is markedly different from the adult. Neonates are especially sensitive to changes in environment, such as temperature, and also many drugs including anaesthetic agents. They are also susceptible to bradycardia, apnoea, and hypotension. ${ }^{1}$ Paediatric general anaesthesia carries with it a higher risk of adverse events with particularly high rates in intubated children, the ASA groups 3-4 and neonates. ${ }^{2}$ In premature babies, where difficulties are often encountered discontinuing ventilation, the ideal anaesthetic agent causes minimal physiological disturbance avoiding the need for reintubation. Ketamine fulfils this requirement. It is short acting, but has a prolonged analgesic effect. It also increases airway tone and often obviates the need for a change in the type of airway being used. ${ }^{3}$

In our hospital, a tertiary referral centre, we perform ROP treatment under ketamine sedation in a dedicated laser room on the neonatal unit. The use of ketamine sedation in this situation allows the laser to be performed in a ward setting and avoids the potential risk of general anaesthesia and inter- and intra-hospital transfer. In this study, we present the results of babies treated in this manner over a 2-year period.

\section{Materials and methods}

All babies undergoing treatment for ROP were included in the study. The ROP laser treatment was carried out by two ophthalmologists and any baby requiring treatment was anaesthetised by a dedicated paediatric anaesthetist (MOM).

The babies underwent ketamine anaesthesia. An empirical initial dose of $0.5 \mathrm{mg} / \mathrm{kg}$ was given, with further increments every $2 \mathrm{~min}$ if the
Received: 3 May 2006 Accepted in revised form: 30 November 2006 Published online: 6 April 2007

\section{Introduction}

The anaesthesia used in retinopathy of prematurity (ROP) treatment varies widely 
child became distressed when trying to insert the speculum. If the child started to move or exhibit distress during the procedure, then the anaesthesia was then increased further. All babies were also given atropine to minimise the salivation effect seen with ketamine and to decrease the oculocardiac reflex. There was no change in the management of the babies' airway during the procedure. Ventilatory support at the time of treatment varied from continuous positive airway pressure ventilation (CPAP) to nasal speculae to air.

Data were collected on their ventilation status pre-, intra-, and postprocedure. Any change in their cardiac or respiratory status during or in the subsequent 3 days following the treatment was noted. An episode of bradycardia or desaturation was recorded as a complication.

\section{Results}

In total, 11 babies, 22 eyes, required treatment over this period with a total of 14 sessions. Three babies required two treatment sessions. This was because in these cases only one eye was at threshold at the time of the initial treatment and the other progressed to threshold ROP later.

The average age at birth was 25 weeks $(23+6-27)$ and at treatment 40 weeks (36-55). The babies ranged from 500 to $1000 \mathrm{~g}$ at birth (average $695 \mathrm{~g}$ ) and at treatment the weight ranged between 1500 and $2840 \mathrm{~g}$ (average $1850 \mathrm{~g}$ ) (Table 1).

The procedure was well tolerated with only three babies having intraoperative complications, which all resolved spontaneously. Two babies had postoperative complications requiring additional ventilation; baby 2 required CPAP overnight and baby 5 was ventilated overnight and then went onto CPAP for 3 days (Table 2).
In no case was the procedure abandoned owing to anaesthetic complications. Significant patient movement was reported in three cases, but the procedure could be completed in all cases.

At the time of follow-up all patients had begun successful regression of neovascularisation.

\section{Discussion}

ROP is a well-recognised complication of low birth weight babies. Untreated it can cause severe visual impairment. There is increasing evidence that early treatment of ROP is to be recommended to ensure better long-term visual acuity. ${ }^{4}$ Laser treatment is now widely recognised as an acceptable treatment method for ROP as it requires less manipulation and causes less trauma than cryotherapy.

Table 1 Demographic data on babies treated

\begin{tabular}{cccccl}
\hline Baby & $\begin{array}{c}\text { Age at } \\
\text { birth } \\
\text { (weeks) }\end{array}$ & $\begin{array}{c}\text { Age at } R_{x} \\
\text { (weeks) }\end{array}$ & $\begin{array}{c}\text { Birth weight } \\
(g)\end{array}$ & $\begin{array}{c}R_{x} \text { weight } \\
(g)\end{array}$ & $\begin{array}{l}\text { Incidence } \\
\text { of chronic } \\
\text { lung disease }\end{array}$ \\
\hline 1 & 27 & $\begin{array}{c}\text { 1st: } 45 \\
\text { 2nd: } 55\end{array}$ & 520 & 1600 & Yes \\
& & 38 & 1000 & 2840 & Yes \\
2 & 26 & 38 & & 2820 & \\
& 26 & $38+2$ & 660 & 1960 & Yes \\
3 & $25+4$ & 39 & 780 & 1520 & Yes \\
4 & 25 & 37 & 600 & 1930 & Yes \\
5 & 27 & 36 & 680 & 1500 & Yes \\
6 & $26+2$ & 39 & 625 & 2100 & Yes \\
7 & $23+6$ & $36+5$ & 360 & 1500 & Yes \\
8 & $24+6$ & 36 & 595 & 2760 & Yes \\
9 & $27+5$ & 43 & 580 & 2100 & Yes \\
10 & 26 & $35+5$ & 4800 & 2900 & Yes \\
11 & $25+3$ & 38 & 800 & 2900 & \\
& & 39 & & &
\end{tabular}

Table 2 Details of anaesthetic agents given, complications, and duration of procedure

\begin{tabular}{|c|c|c|c|c|c|c|c|c|}
\hline Baby & $\begin{array}{l}\text { Ventilation } \\
\text { at } R_{x}\end{array}$ & $\begin{array}{l}\text { Intraoperative } \\
\text { complication }\end{array}$ & $\begin{array}{l}\text { Postoperative } \\
\text { complication }\end{array}$ & $\begin{array}{l}\text { Postoperative } \\
\text { ventilation }\end{array}$ & $\begin{array}{c}\text { Dose ketamine } \\
\text { given }\end{array}$ & $\begin{array}{c}\text { Dose ketamine } \\
m g / k g\end{array}$ & $\begin{array}{l}\text { Other } \\
\text { agent }\end{array}$ & $\begin{array}{l}\text { Length } \\
\text { (h) }\end{array}$ \\
\hline $1 \mathrm{R}$ & CPAP & Nil & Nil & CPAP & $5 \mathrm{mg}$ & 3.1 & Atropine & 2 \\
\hline $\mathrm{L}$ & CPAP & Nil & Nil & CPAP & $5 \mathrm{mg}$ & 2.7 & Atropine & 2 \\
\hline $2 \mathrm{R}$ & Nasal spec & Nil & Nil & Nasal Spec & $8 \mathrm{mg}$ & 2.8 & Atropine & 2 \\
\hline $\mathrm{L}$ & Nasal spec & Nil & brady \& desat & CPAP & $7 \mathrm{mg}$ & 2.5 & Atropine & 1.75 \\
\hline 3 & Air & $1 \times$ desat & Nil & Air & $2 \mathrm{mg}$ & 1 & Atropine & 1.25 \\
\hline 4 & Nasal spec & Nil & Nil & Nasal spec & $1 \mathrm{mg}$ & 0.7 & Midazolam & 1.5 \\
\hline 5 & Nasal spec & Nil & $3 \times$ desat & IPPV & $5 \mathrm{mg}$ & 2.6 & Atropine & 2 \\
\hline 6 & CPAP & $1 \times$ brady & Nil & CPAP & $6 \mathrm{mg}$ & 4 & Atropine & 1 \\
\hline 7 & Air & $1 \times$ desat & Nil & Air & $8 \mathrm{mg}$ & 3.8 & Atropine & 1.5 \\
\hline 8 & CPAP & Nil & Nil & CPAP & $2 \mathrm{mg}$ & 1.3 & Atropine & 2 \\
\hline 9 & Nasal spec & Nil & Nil & Nasal spec & $5 \mathrm{mg}$ & 1.8 & Atropine & 1.5 \\
\hline 10 & CPAP & Nil & Nil & CPAP & Unknown & Unknown & Atropine & 1.5 \\
\hline $11 \mathrm{R}$ & Nasal spec & $2 \times$ desat & Nil & Nasal spec & $3.5 \mathrm{mg}$ & 1.2 & Atropine, & 1.5 \\
\hline
\end{tabular}


Previous studies have examined the use of topical anaesthetic, general anaesthetic, and combinations of sedation and analgesia ${ }^{5}$ during the treatment by cryotherapy of ROP. Haigh et $a l^{5}$ found that the incidence of cardiovascular and respiratory complications greatly increased with the use of topical anaesthetic, but that the performance of the procedure under general anaesthetic or sedation/analgesia was comparable. Other studies have looked at the use of remifentanil as an anaesthetic agent in patients having cryotherapy for ROP. The results in this study showed few respiratory complications, but all infants required intubation during the procedure. ${ }^{6}$ Re-intubation is not ideal in premature babies where they have often had difficulty weaning them off ventilation initially and who are at greater risk of adverse events from intubation. ${ }^{2}$

However, for ROP treatment by laser there is still wide variation in the type of anaesthetic used. In our unit, we use ketamine. Ketamine is a short-acting 'dissociative' anaesthetic with a potent analgesic effect that lasts longer than the period of anaesthesia, and this analgesic effect occurs even at subanaesthetic doses. The 'dissociative' property means that it gives complete anaesthesia and analgesia while preserving vital brain stem functions. ${ }^{3}$ Ketamine increases airway tone and thus preserves airway patency ${ }^{7}$ and respiratory function and while some studies suggested that it caused mild respiratory depression, ${ }^{7}$ this has not been shown in other studies. ${ }^{3}$ Ketamine does, however, cause salivation and therefore all babies in this study were given atropine to minimise this and to dampen the oculocardiac reflex. It has also been reported that ketamine causes hallucinations and, while it is difficult to measure this in neonates, the nurses did not report any changes in the behaviour of the children after the procedure, which would suggest that any such event was minimal.

The use of ketamine allows the treatment to be given in a dedicated room on the neonatal unit. This allows the baby to remain in an environment where temperature is closely regulated and avoids the possible stress of temperature change known to be associated with apnoea. ${ }^{8}$ In a grade 3 neonatal unit, it is also possible for the procedure to be performed with neonatal staff, rather than anaesthetic, support. This is because by using ketamine these babies do not require intubation and usually do not require any change from their initial airway management.

Preterm infants are more likely to suffer postoperative apnoea and cardiovascular complications than other children following general anaesthesia ${ }^{8,9}$ and 20-30\% develop apnoea even without the stress of general anaesthesia. ${ }^{10}$ The results of our study showed that there were few respiratory complications with our technique, which would support the use of ketamine in this at risk group. Another issue that may have caused concern with the use of a sedative technique was that patient movement would compromise the ability to perform the procedure. However, despite significant movement in three cases all procedures could be completed.

In conclusion, the use of ketamine sedation has been found to produce few intra- or postoperative complications for the infant while providing satisfactory conditions for the treatment of ROP. Its use avoids the possible complications of inter- and intra-hospital transfer as well as avoiding general anaesthetic in babies, which already have many coexisting medical problems. We would recommend that the use of ketamine and other sedative techniques be considered for use in ROP treatment.

\section{References}

1 Hillier SC, Krishna G, Brasoveanu E. Neonatal anaesthesia. Semin Pediatr Surg 2004; 13(3): 142-151.

2 Murat I, Constant I, Maud'huy H. Perioperative anaesthetic morbidity in children: a database of 24165 anaesthetics over a 30-month period. Paediatr Anesth 2004; 14(2): 158-166.

3 White PF, Way WL, Trevor AJ. Ketamine - its pharmacology and therapeutic uses. Anesthesiology 1982; 56(2): 119-136.

4 Early treatment for Retinopathy of Prematurity Cooperative Group. Revised indications for the treatment of retinopathy of prematurity. Arch Ophthalmol 2003; 121: 1684-1694.

5 Haigh PM, Chiswick ML, O'Donoghue EP. Retinopathy of prematurity: systemic complications associated with different anaesthetic techniques at treatment. $\mathrm{Br} J$ Ophthalmol 1997; 81(4): 283-287.

6 Sammartino M, Bocci MG, Ferro G, Mercurio G, Papacci P, Conti $\mathrm{G}$ et al. Efficacy and safety of continuous intravenous infusion of remifentanil in preterm infants undergoing laser therapy in retinopathy of prematurity: clinical experience. Paediatr Anaesth 2003; 13(7): 596-602.

7 Reich D, Silvay G. Ketamine: an update on the first twentyfive years of clinical experience. Can J Anaesthesia 1989; 36(2): 186-197.

8 Ray M, Saha E. Complications following general anaesthetic in paediatric patients. Indian J Anaesth 2004; 48(5): 400-405.

9 Welborn L, Rice L, Hannallah RS, Broadman LM, Ruttimann UE, Fink R. Postoperative apnoea in former preterm infants: prospective comparison of spinal and general anesthesia. Anesthesiology 1990; 72: 838-842.

10 Gregory G, Steward D. Life threatening perioperative apnoea in the Ex-'premie'. Anesthesiology 1983; 59: 495-498. 